\title{
The Olfactory Tubercle Encodes Odor Valence in Behaving Mice
}

\author{
๑Marie A. Gadziola, ${ }^{1}$-Kate A. Tylicki, ${ }^{2}$ Diana L. Christian, ${ }^{1}$ and ${ }^{-D a n i e l ~ W . ~ W e s s o n ~}{ }^{1,2}$ \\ ${ }^{1}$ Department of Neurosciences, School of Medicine, and ${ }^{2}$ Department of Biology, Case Western Reserve University, Cleveland, 0 hio 44106
}

\begin{abstract}
Sensory information acquires meaning to adaptively guide behaviors. Despite odors mediating a number of vital behaviors, the components of the olfactory system responsible for assigning meaning to odors remain unclear. The olfactory tubercle (OT), a ventral striatum structure that receives monosynaptic input from the olfactory bulb, is uniquely positioned to transform odor information into behaviorally relevant neural codes. No information is available, however, on the coding of odors among OT neurons in behaving animals. In recordings from mice engaged in an odor discrimination task, we report that the firing rate of OT neurons robustly and flexibly encodes the valence of conditioned odors over identity, with rewarded odors evoking greater firing rates. This coding of rewarded odors occurs before behavioral decisions and represents subsequent behavioral responses. We predict that the OT is an essential region whereby odor valence is encoded in the mammalian brain to guide goal-directed behaviors.
\end{abstract}

Key words: associative learning; odor discrimination; olfaction; olfactory cortex; sensory coding

\section{Introduction}

Sensory information acquires meaning to adaptively guide our essential behaviors. Both cortical and subcortical structures are believed to work together to assign valence to stimuli (Berridge and Aldridge, 2008; Gottfried, 2009; Veldhuizen et al., 2009; Pessoa and Adolphs, 2010; Kumar et al., 2012; Chikazoe et al., 2014); however, major questions remain regarding the circuitry underlying this important task. Odors guide a number of vital behaviors, such as nutritional selection and threat avoidance (Doty, 1986; Slotnick, 2001). Both the olfactory bulb (Pager, 1974; Karpov, 1980; Wilson et al., 1987; Kay and Laurent, 1999; Doucette et al., 2011) and piriform cortex (Schoenbaum and Eichenbaum, 1995; Litaudon et al., 1997; Cohen et al., 2008; Gottfried, 2010; Wilson and Sullivan, 2011; Gire et al., 2013) possess the capacity to code for odors based upon their associative properties. The fact that odor information from the olfactory bulb is directly distributed to multiple secondary olfactory structures in addition to the piriform cortex (Shipley and Adamek, 1984; Scott, 1986) suggests that the olfactory system may use parallel pathways for encoding odor meaning.

We predicted that the olfactory tubercle (OT) participates in the coding of odor valence. The OT is a component of both the olfactory and reward systems (de Olmos and Heimer,

Received Nov. 19, 2014; revised Feb. 2, 2015; accepted Feb. 4, 2015.

Author contributions: M.A.G. and D.W.W. designed research; M.A.G. and K.A.T. performed research; M.A.G., K.A.T., D.L.C., and D.W.W. analyzed data; M.A.G. and D.W.W. wrote the paper.

This work was supported by grants from the National Science Foundation (ISO-1121471), the Alzheimer's Association (14-305847), and the Mt. Sinai Healthcare Foundation. We thank Dr. J. Cohen for advice regarding receiver operating characteristic analysis during early stages of this study.

The authors declare no competing financial interests.

Correspondence should be addressed to Daniel W. Wesson, Department of Neurosciences, Case Western Reserve University School of Medicine, 2109 Adelbert Road, Cleveland, OH 44106. E-mail: dww53@case.edu.

DOI:10.1523/JNEUROSCI.4750-14.2015

Copyright $\odot 2015$ the authors $\quad 0270-6474 / 15 / 354515-13 \$ 15.00 / 0$
1999). Olfactory information is conveyed to the OT through a number of pathways, including monosynaptic input from the olfactory bulb and inputs from other olfactory cortical areas, as well as the amygdala and orbitofrontal cortex (Wesson and Wilson, 2011). In anesthetized animals, OT neurons readily encode odor information and are modulated by multisensory inputs (Murakami et al., 2005; Wesson and Wilson, 2010; Payton et al., 2012; Rampin et al., 2012). State-dependent influences also modulate cellular and network-level activity of the OT in awake rodents (Carlson et al., 2014; Narikiyo et al., 2014) and in humans (Zelano et al., 2005). No description of cellular-level odor coding in the OTs of awake animals is available.

The OT is also a part of the ventral striatum reward circuitry that connects limbic and basal ganglia systems to facilitate behavioral learning (Mogenson et al., 1980; Cardinal et al., 2002; Ikemoto, 2007; van der Meer and Redish, 2011). Indeed, the OT possesses dense reciprocal connectivity with the nucleus accumbens, ventral tegmental area, and multiple amygdaloid nuclei, as well as outputs to basal ganglia including the caudate-putamen (for review, see Wesson and Wilson, 2011). Further, the OT has established roles in driving reward-directed motivated behaviors (Prado-Alcalá and Wise, 1984; Ikemoto, 2003; Ikemoto et al., 2005).

Thus, based upon both functional and anatomical data, there are two seemingly distinct theories for the role of the OT-one for sensory processing, especially olfaction, and one for motivated behaviors. Here, we tested the hypothesis that OT neurons code the associated outcome of odors (rewarded or not), which has the potential to unite these two views. We find that the firing rate of OT neurons robustly and flexibly encodes the learned valence of odors in a manner that may be important for guiding instrumental behavior. 


\section{Materials and Methods}

Animals. C57BL/6 male mice $(n=18,2-4$ months of age) originating from Harlan Laboratories were bred and maintained within the Case Western Reserve University School of Medicine animal facility. Two animals did not contribute data since one did not yield well isolated neurons and the other did not reach criterion behavioral performance levels. Mice were housed on a $12 \mathrm{~h}$ light/dark cycle with food and water available ad libitum, except when water was restricted for behavioral training (see below). Up to five mice were cohoused in a cage before experimentation, but all postsurgical animals were housed individually. All experimental procedures were conducted in accordance with the guidelines of the National Institutes of Health and were approved by the Case Western Reserve University Institutional Animal Care Committee.

Surgical procedures. Mice were anesthetized with isoflurane (2-4\% in oxygen; Abbott Laboratories) and mounted in a stereotaxic frame with a water-filled heating pad $\left(38^{\circ} \mathrm{C}\right)$ beneath to maintain body temperature. Anesthesia depth was verified by the absence of the toepinch reflex. An injection of a local anesthetic ( $1 \%$ lidocaine, $0.05 \mathrm{ml}$, s.c.) was administered into the wound margin site before exposing the dorsal skull. A craniotomy was made to access the OT $(+2.0 \mathrm{~mm}$ from bregma, $+1.0 \mathrm{~mm}$ lateral; Fig. 1). An eight-channel tungsten electrode array was implanted within the OT (4.9 $\mathrm{mm}$ ventral) and cemented in place, along with a headbar for later head fixation. A second craniotomy was made over the contralateral cortex for placement of a ground wire. To access respiratory transients (Wesson et al., 2008), a small hole was drilled into the ipsilateral nasal bone, $1 \mathrm{~mm}$ anterior to the frontal nasal fissure. The nasal epithelium was pierced, and a small stainless steel cannula (part \#C313G, PlasticsOne) was secured in place. During a $3 \mathrm{~d}$ recovery period, animals received a daily injection of carprofen $(5 \mathrm{mg} / \mathrm{kg}$, s.c.; Pfizer Animal Health) and ad libitum access to food and water.

Behavioral task. Mice were water restricted for $3 \mathrm{~d}$ before behavioral training. Body weight was monitored daily and maintained at $85 \%$ of their original weight. Mice were trained in cohorts of three. All behavioral procedures were performed during the light hours. Head-fixed mice were trained on a lick/no-lick odor discrimination task across multiple $1 \mathrm{~h}$ recording sessions in which the mice obtained a $4 \mu \mathrm{l}$ water reward for licking a spout positioned in front of their snouts in trials with reinforced odors (Fig. 2A-C; Verhagen et al., 2007). Licking was measured by a pair of infrared photobeams positioned to cross in front of the lick spout by $\sim 2 \mathrm{~mm}$. Mice were first trained to lick the water spout for reward (Phase 1) and then were rewarded for licking only during odor presentation (Phase 2, always rewarded odor trials), with a progressively increasing intertrial interval. In Phase 3, trials were randomized between rewarded and unrewarded trials; for unrewarded odor trials, mice were presented with a "blank" stimulus (mineral oil) and had to learn to withhold licking during these trials. Finally, in Phase 4, trials were randomized between the rewarded and unrewarded odor as in the experimental sessions. In go trials, mice would receive a reward for licking a spout during the rewarded odor (hit), otherwise the trial would be considered a miss. In no-go trials, mice were presented with an unreinforced odor and did not receive a water reward regardless of whether they licked (false alarm) or correctly withheld licking for the total odor duration of the trial (correct reject). Behavioral performance was evaluated in blocks of 20 trials, and mice were required to achieve a performance criterion of $\geq 85 \%$ correct

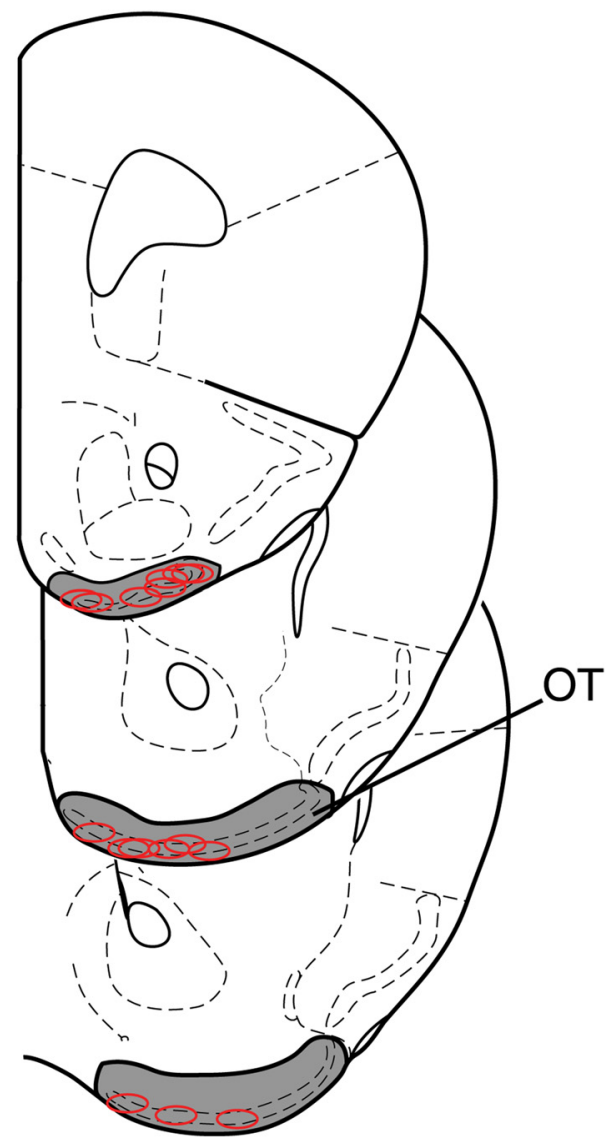

Figure 1. Electrode tip locations within the $0 \mathrm{O}$. Coronal panels show the approximate location of electrode tips following histological verification (red ellipses, $n=16$ separate implants). All recordings had electrode tips confirmed within the 0 T, with the majority of tips localized within the anterior portion of the $0 \mathrm{~T}$. The extent of the $0 \mathrm{~T}$ is indicated by gray shading. Placement within a specific layer of the $0 \mathrm{~T}$ could not be resolved. Sections span from 1.0 to $2.0 \mathrm{~mm}$ anterior of bregma (gray line), in $0.5 \mathrm{~mm}$ intervals. Panels are adapted from Paxinos and Franklin (2000).

for two consecutive blocks to advance to the next phase (Fig. 2C; Verhagen et al., 2007). OT activity was recorded throughout all training phases, but analysis of odor-evoked activity was restricted to post-training sessions.

On separate experimental days, mice were evaluated under three different behavioral tasks, in the following order: odor discrimination, binary odor mixture discrimination, and reversal learning. For odor discrimination sessions ( $n=52$ sessions total), 16 mice had extensive training with an odor pair, as evidenced by high behavioral performance ( $\geq 80 \%$ correct). One mouse did not yield any well isolated neurons during this task. Analyses for this task type included responses to the original odor pair used during the training phases, as well as novel odor pairs that were learned in a later session (see below). In binary odor mixture discrimination sessions ( $n=25$ sessions total), task difficulty was increased for 13 mice by using binary mixtures of the rewarded and unrewarded odors (Uchida and Mainen, 2003; Abraham et al., 2004). The first cohort of mice $(n=3)$ did not participate in a binary odor mixture discrimination task. Binary mixtures were presented at ratios of $80 \%$ rewarded to $20 \%$ unrewarded (in the liquid state). One mouse did not reach adequate behavioral performance levels in the mixture discrimination task. For reversal learning sessions ( $n=17$ sessions total), 16 mice were presented with the original odor discrimination pair for two blocks, after which the odor contingencies were reversed and successful reversal learning was acquired within the same day. Two mice did not yield well isolated neurons during the reversal learning task, and a third mouse did not reach criterion behavioral performance levels. After completing all tasks, eight mice were trained on additional novel odor discriminations followed by reversal learning to increase the yield of unique neuron-odor pairings (maximum of three unique odor pairings per 
A

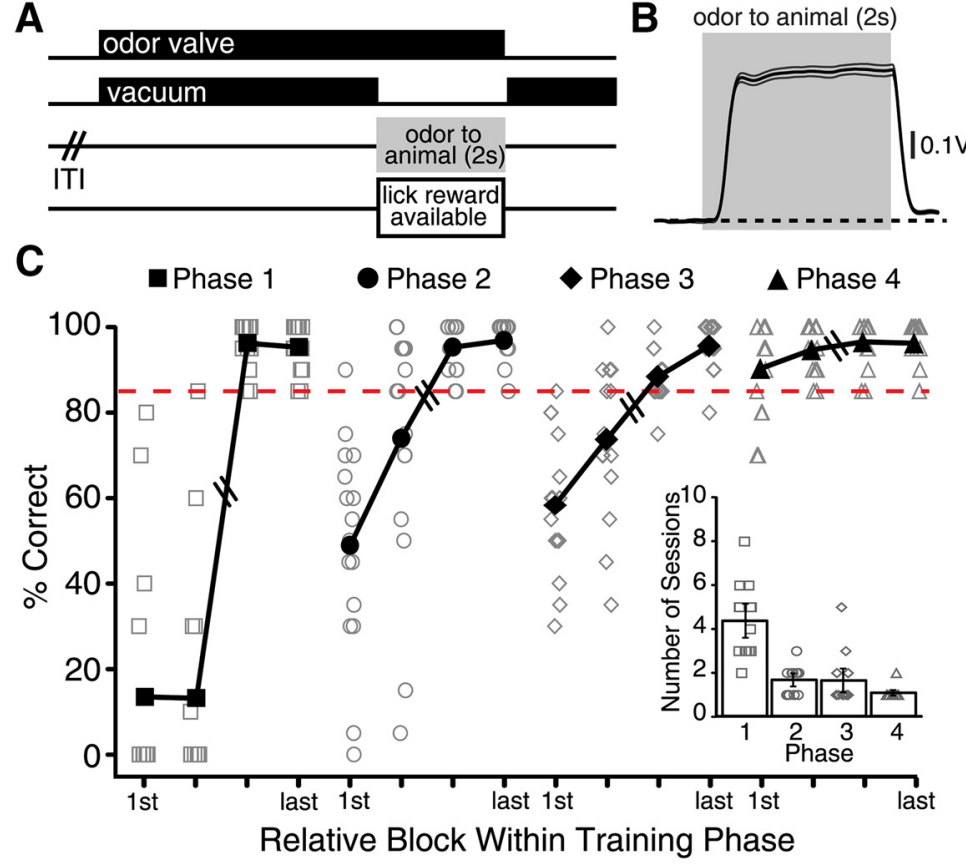

Figure 2. Experimental trial outline and example behavioral performance during training. $A$, After a variable intertrial interval (ITI), the odor and vacuum solenoid valves were turned on for $13 \mathrm{~s}$, after which the vacuum would turn off for $2 \mathrm{~s}$, allowing for the odor to flow toward the nose of the animal. A water reward was available if animals licked a spout during rewarded odors, but not for licking during unrewarded odors. B, Average evoked PID trace in response to eight presentations of 1,7-octadiene, illustrating the rapid temporal dynamics ( $\sim 110$ and $120 \mathrm{~ms}$ at $10 \%$ and $50 \%$ of baseline, respectively) and stability of odor presentation ( $3 \mathrm{~Hz}$, low-pass, second-order filter). Dashed horizontal line indicates the average baseline. C, Average behavioral performance in the first two and last two blocks of the four training phases (for details, see Materials and Methods). After meeting high-performance criterion for at least two consecutive blocks (red dashed line), animals were advanced to the next training phase. Chance performance is $50 \%$ correct. Not all mice performed the same number of blocks per phase. Inset, Average number of sessions per training phase. Data from individual mice are plotted in gray. Jitter was added to data along the $x$-axis to help visualize overlapping points. On average, the 16 mice used for data analysis in this study learned the task to criterion performance after $8.8 \pm 0.7$ training sessions (inset), and their average block performance was $88 \pm 2 \%$ correct responses across all odor discrimination experimental sessions.

mouse). Overall, one to eight sessions per mouse were performed for the original discrimination task, and one to three sessions per mouse for the binary mixture and reversal tasks.

Stimulus delivery. Odors were presented through a custom air dilution olfactometer with independent stimulus lines up to the point of entry into the odor port. In addition to a blank stimulus (mineral oil), odors included isopentyl acetate, ethyl propionate, ethyl butyrate, heptanal, (-)-limonene, 2-heptanone, 2-butanone, and 1,7-octadiene (Sigma-Aldrich; all $>97 \%$ purity). These molecularly diverse odors were diluted in their liquid state to 1 torr $(133.32 \mathrm{~Pa})$ in mineral oil and were then further diluted to $10 \%(\mathrm{v} / \mathrm{v})$ by mixing $100 \mathrm{ml}$ of odor vaporized $\mathrm{N}_{2}$ with $900 \mathrm{ml}$ of medical grade $\mathrm{N}_{2}$ (Airgas). Thus, stimuli were delivered at a total flow rate of $1 \mathrm{~L} / \mathrm{min}$. Not all animals were tested with all odors. The rewarded and unrewarded odor pairs were pseudo-randomly assigned to each cohort before training (neurons were not initially screened for odor responsiveness). The experimenter was not blind to odor assignment, but all stimulus presentation was automated. Rewarded and unrewarded odors were pseudo-randomized within each block, and presented for $2 \mathrm{~s}$ duration with a $25 \pm 2 \mathrm{~s}$ intertrial interval through a Teflon odor port (9-mm-diameter opening) directed toward the snout of the animal at a distance of $1 \mathrm{~cm}$. Odor was continuously flowing to the odor port but was removed by a vacuum before exiting toward the animal. Recordings with a photoionization detector (PID; miniPID, Aurora Scientific) were used to confirm the temporal dynamics of the odor presentation in this design. When a single test stimulus (1,7-octadiene, diluted and presented as described above) was presented eight times, the average evoked PID response reached $10 \%$ and $50 \%$ of maximum response at $\sim 110$ and 120 $\mathrm{ms}$, respectively, relative to vacuum offset (odor onset; Fig. $2 B$ ). The intensity of the odor was relatively stable throughout the duration of the
2 s presentation ( $\pm 3 \%$ of the mean). Further, odor removal was rapid, with a prompt return of the PID response to $<10 \%$ of the maximum response following vacuum onset (odor offset). While these dynamics may vary slightly across odors, these measures illustrate the precision and stability of the odor presentation methods used in this study.

In vivo electrophysiology. The output of the electrode array was amplified, digitized at 24.4 $\mathrm{kHz}$, filtered (bandpass filter, 300-5000 Hz), and monitored (Tucker-Davis Technologies), along with respiration (bandpass filter, $1-10$ $\mathrm{Hz} ; 100 \mathrm{~Hz}$ sampling rate), licking $(300 \mathrm{~Hz}$ sampling rate), and odor presentation events. One electrode wire was selected to serve as a local reference. To aid behavioral shaping, sniffing was monitored in eight animals by recording intranasal pressure by connecting the implanted nasal cannula to a pressure sensor (Honeywell) via polyethylene tubing (Wesson et al., 2008). No attempt was made to analyze data relative to the respiratory cycle among these animals due to a limited number of experimental sessions with a robust sniffing signal. Given the small dorsal-ventral extent of the OT $(\sim 300 \mu \mathrm{m})$, our electrode arrays were fixed in place, and no attempt was made to record from unique populations of neurons on different sessions. Indeed, it is possible that the same neuron was recorded across multiple days. To compensate for this potential bias, the three different behavioral tasks and/or novel odor pairs were used, and statistical comparisons were made only within each task type. Sessions of the same task and odor pair were run for 1-3 consecutive days to achieve adequate behavioral performance and/or capture the dynamics of newly identified neurons. Examination of the average spike waveform confirmed that $89 \%$ of the analyzed neurons represent a unique neuron-odor pair. On average, $3.1 \pm 1.4$ single neurons were recorded per mouse per session (range, one to seven neurons), with an average of $2.2 \pm 1.6$ neurons recorded per viable electrode wire per mouse per session. After all recording sessions were completed (between 10 and $30 \mathrm{~d}$ ), mice were given (intraperitoneally) an overdose of urethane and were transcardially perfused with $0.9 \%$ saline and $10 \%$ formalin, and brains stored in $30 \%$ sucrose formalin at $4^{\circ} \mathrm{C}$. OT recording sites were verified by histological examinations of slide-mounted, $40 \mu \mathrm{m}$ coronal sections stained with a $1 \%$ cresyl violet solution (Fig. 1).

Analysis of odor-evoked activity. Single neurons were sorted off-line in Spike2 (Cambridge Electronic Design), using a combination of template matching and cluster cutting based on principal component analysis. Single neurons were further defined as having $<2 \%$ of the spikes occurring within a refractory period of $2 \mathrm{~ms}$. Spike times associated with each odor were extracted and exported to MATLAB (MathWorks) for further analysis. To examine modulations in firing rate within a single trial, spike density functions were calculated by convolving spike trains with a function resembling a postsynaptic potential (Thompson et al., 1996). Mean firing rates across trials were measured in $50 \mathrm{~ms}$ bins, along with the $95 \%$ confidence intervals. The mean baseline firing rate for each neuron was averaged across the $2 \mathrm{~s}$ before odor onset. Neurons were considered task-responsive if two consecutive bins within a $7 \mathrm{~s}$ period from odor onset were significantly different from the baseline rate, having nonoverlapping confidence intervals. This liberal $7 \mathrm{~s}$ window size was chosen to capture any modulation in firing rate that may be related to odor presentation, licking behavior, and/or reward ingestion. Notably, our results are not dependent on the size of this window. Indeed, almost all responsive 
neurons in the odor discrimination task (164 of 165 neurons) are also task responsive within a $2 \mathrm{~s}$ period from odor onset.

Animals were typically presented with 40 trials of a single rewarded and unrewarded odor set per session. To ensure that animals were attending to the task, only blocks possessing high behavioral performance were analyzed for odor discrimination and reversal learning sessions. For the binary odor mixture discrimination task, all blocks were analyzed regardless of performance due to the increased task difficulty and the need for comparing correct and error trials. All performed tests were two sided and met assumptions of normality (Kolmogorov-Smirnov test). Sample sizes are consistent with numbers reported in the field, and no statistical method was used to predetermine these. Statistical analyses were performed in StatView (SAS Institute) or MATLAB. All data are reported as the mean \pm SEM, unless otherwise noted.

Receiver operating characteristic analysis. The area under the receiver operating characteristic (auROC) is a nonparametric measure of the discriminability of two distributions (Green and Swets, 1966). To normalize peristimulus time histograms across neurons, we used an auROC method that quantifies stimulusrelated changes in firing rate to the baseline activity on a $0-1$ scale (for more details, see Cohen et al., 2012). A value of 0.5 indicates completely overlapping distributions, whereas values of 0 or 1 signal perfect discriminability. Using a sliding ROC analysis, we calculated the auROC at each time bin (window size $50 \mathrm{~ms}$, advanced in $10 \mathrm{~ms}$ steps) over a $7 \mathrm{~s}$ period from stimulus onset. Values $>0.5$ indicate the probability that firing rates were increased relative to baseline, whereas values $<0.5$ indicate the probability that firing rates were decreased relative to baseline. The firing rate distributions of correct trials typically contained 20-40 trials per odor (range, 7-61), except for error trial distributions, which required a minimum of only 5 trials and typically contained 6-25 trials (range, 5-48). Similar trial numbers have been used for calculating auROC (Veit and Nieder, 2013).

To evaluate odor selectivity, auROC was used to measure the discriminability of the firing rate distributions of the rewarded and unrewarded odor (the unrewarded odor was set as the reference distribution). In this case, values $>0.5$ indicate increases in firing for the rewarded odor relative to unrewarded odor ("rewarded odor preference"), whereas values $<0.5$ indicated higher firing rates for the unrewarded odor ("unrewarded odor preference"). A permutation test was used to create a null distribution of auROC values $\sim 0.5$, where the trial labels "rewarded" and "unrewarded' were randomly reassigned and calculated 1000 times. Significant auROC bins were determined by testing whether the actual auROC value was outside the $95 \%$ confidence interval of this null distribution (Veit and Nieder, 2013). A neuron was considered "odor selective" (increased firing rates for one odor over the other) if there were at least two consecutive significant auROC bins from odor onset to the average be-

B
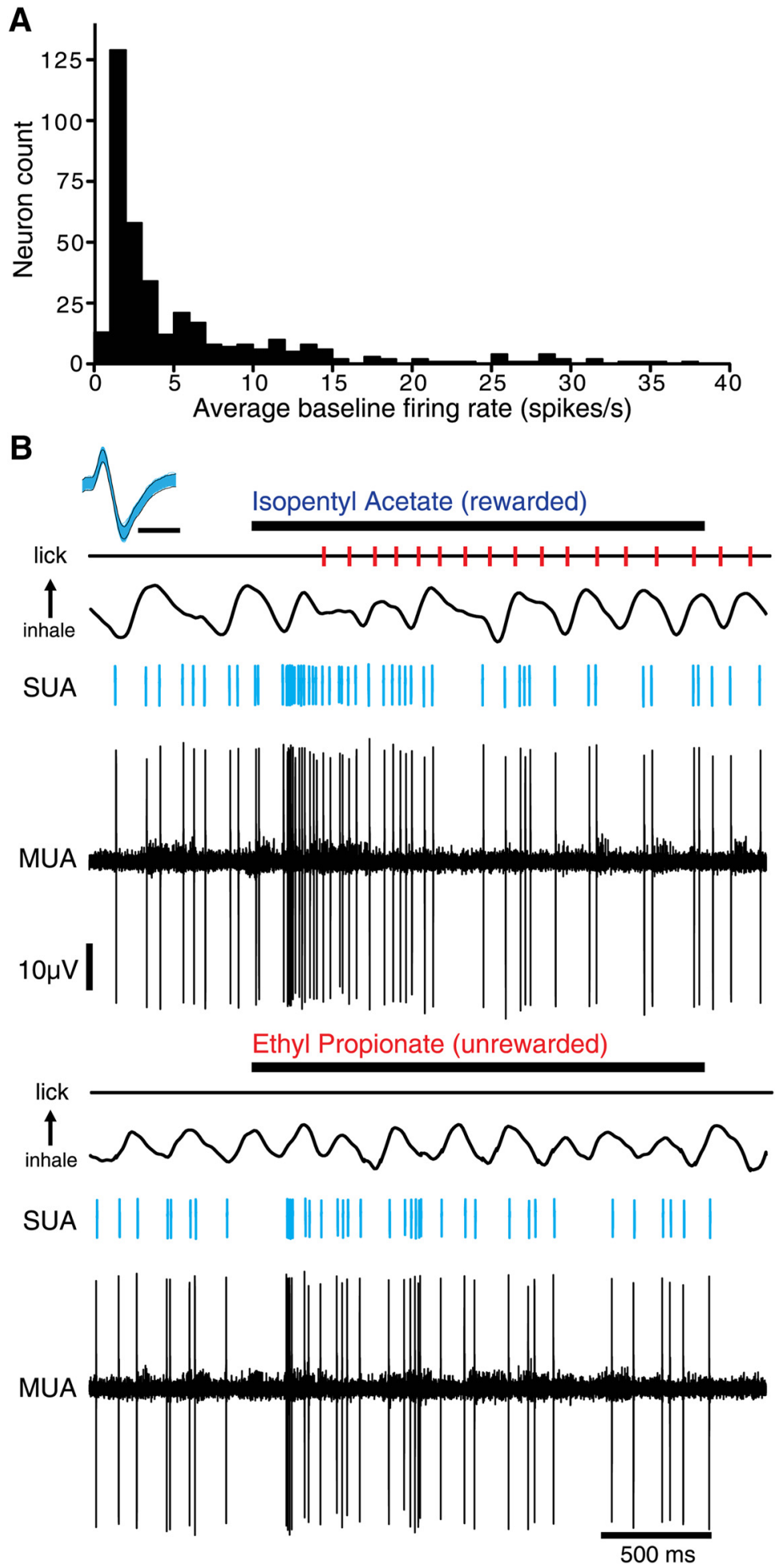

Figure 3. Properties of single-neuron recordings in the $0 T$. $A$, Distribution of average baseline firing rates of all neurons up to 40 spikes/s (median, 1.9 spikes/s; range, $0-77.8$ spikes $/ \mathrm{s}$ ). $\boldsymbol{B}$, Example single-electrode traces in response to a rewarded (top) and unrewarded (bottom) odor aligned with sniffing via the intranasal cannula for illustrative purposes. Multiunit activity (MUA) is spike sorted off-line to identify single-unit activity (SUA) using template matching and cluster cutting with principal component analysis. Red vertical lines on the lick trace indicate the timing of individual licks. Overlaid spike waveforms for the illustrated neuron demonstrate a well isolated single neuron. Calibration: $0.5 \mathrm{~ms}$.

havioral response within the session, which was defined as $75 \mathrm{~ms}$ before the recorded lick onset to adjust for motor responses leading up to lick detection. Odor-selective neurons that preferentially fired in response to the rewarded odor had significant auROC values $(>0.5)$, whereas neu- 
A

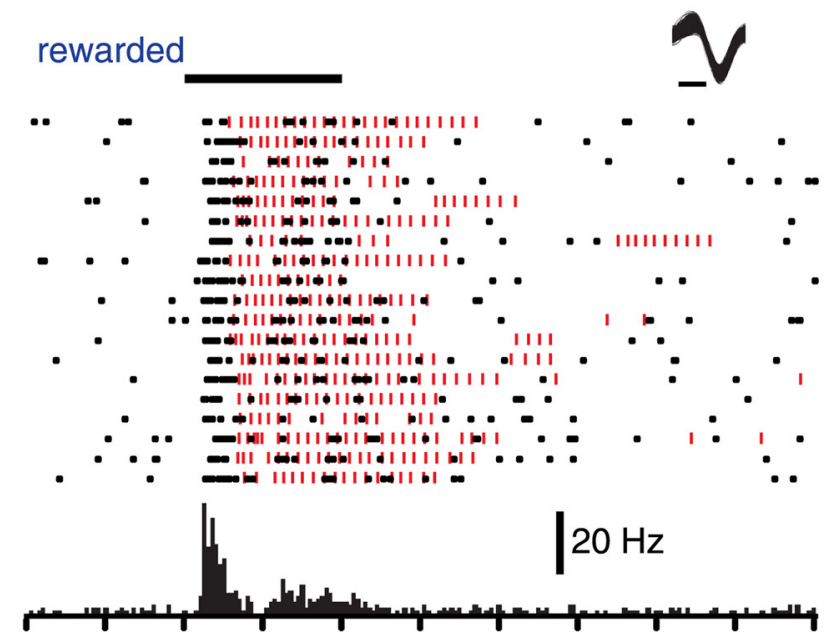

unrewarded
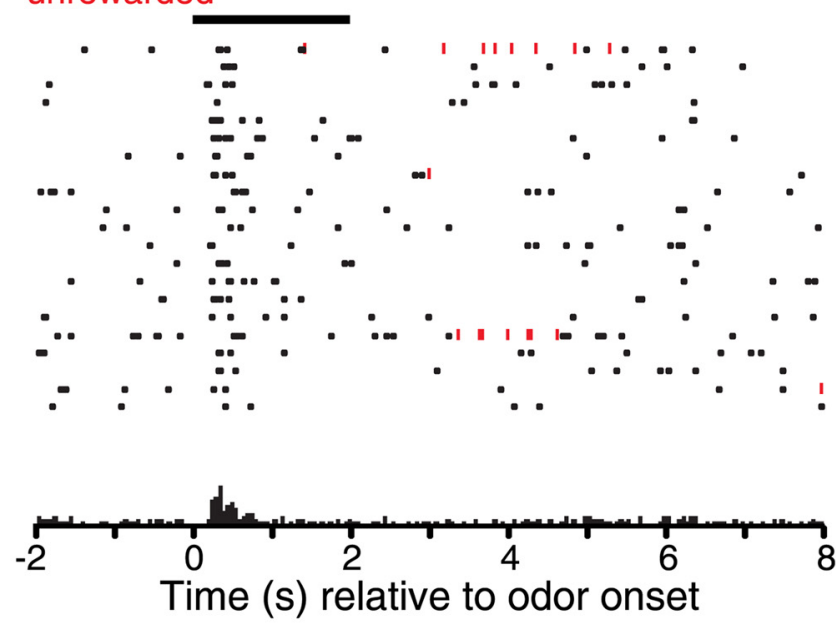

B

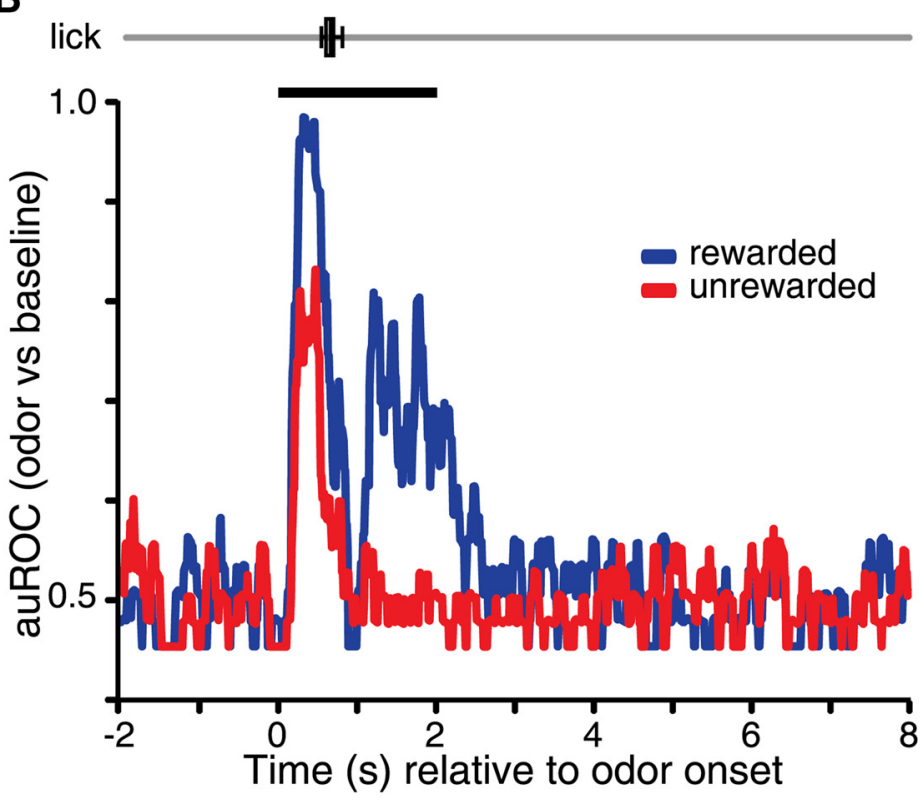

Figure 4. An example $0 \mathrm{~T}$ neuron with stimulus-evoked activity to both conditioned odors. $\boldsymbol{A}$, Example single-neuron raster and peristimulus time histogram in response to a conditioned-rewarded and unrewarded odor. Red vertical lines indicate the timing of detected licks on each trial. Inset, overlapping waveforms of the isolated neuron. Calibration: $0.5 \mathrm{~ms}$. Black horizontal bars indicate the timing of odor stimuli. $\boldsymbol{B}$, auROC values for the same neuron in $\boldsymbol{A}$. Horizontal boxplot shows the range of trial lick onsets for this session (median lick onset, 0.67 s). rons preferentially firing for the unrewarded odor had significant auROC values $(<0.5)$. The same procedure was used for determining trial response selectivity, except in those cases where firing rate distributions were defined by the behavioral response and required the following three comparisons: hit versus correct reject, false alarm versus correct reject, and hit versus false alarm. Population auROC odor comparisons were made by first averaging values across a $200 \mathrm{~ms}$ window before average lick onset for each neuron, and then running a paired $t$ test. To test the strength of discriminability, auROC magnitudes before lick onset for all task-responsive neurons were assessed by first subtracting the auROC value for neurons with "unrewarded odor preference" from 1 , so that both distributions ranged from 0.5 to 1 (Veit and Nieder, 2013).

To investigate the potential influence of licking on the measured neural responses, we tested whether our results were dependent on the inclusion of trials with early lick onsets (those occurring $\leq 200 \mathrm{~ms}$ from odor onset). Responses were then compared when spike times were aligned to lick onset for each rewarded trial. For this analysis, baseline firing rates were measured from -4 to $-2 \mathrm{~s}$ relative to onset. The slope of the initial rise in auROC values was measured from $10 \%$ to $90 \%$ of the maximum auROC value.

\section{Results}

OT neurons show divergent responses to conditioned odors

We monitored OT activity from 16 mice engaged in a head-fixed odor discrimination task requiring them to lick a spout for a water reward when presented with a conditioned-rewarded odor but not an unrewarded odor (Figs. 1, 2). This headfixed paradigm allows odor-guided behaviors while maintaining optimal precision in odor delivery (Verhagen et al., 2007). Baseline and odor-evoked activity were measured for isolated single neurons (Fig. 3). In awake, behaving mice, the baseline rates of OT neurons were low, with a median rate of 1.9 spikes/s (range, $0-77.8$ spikes/s) across the sampled population (Fig. 3A; measured $2 \mathrm{~s}$ before odor onset). Odor-evoked activity was observed with a variety of different odors and occurred shortly after odor onset $(0.37 \pm 0.03$ s; Fig. $3 B)$.

After mice learned the original odor discrimination, we observed that the majority of OT single neurons significantly modulated their firing rate during the task window $(87 \%, 165$ of 190 neurons were "task responsive" within $7 \mathrm{~s}$ of odor onset). To characterize responses across this population, we measured the temporal response profile of each neuron during correct trials by quantifying changes in firing 
$\mathbf{A}_{\text {lick }}$

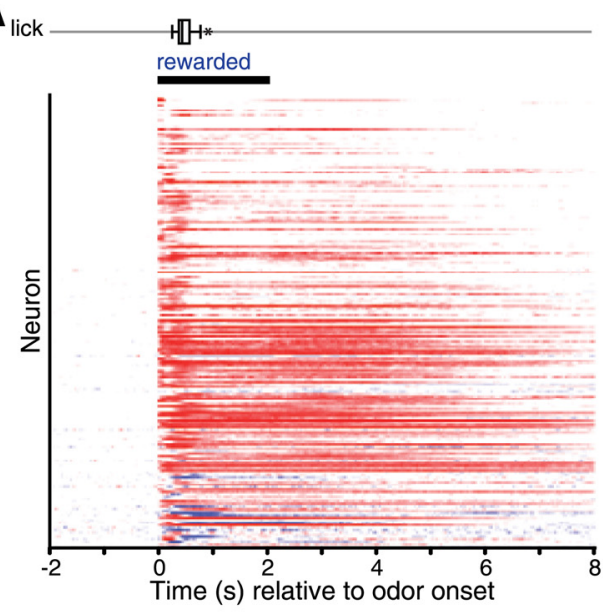

C

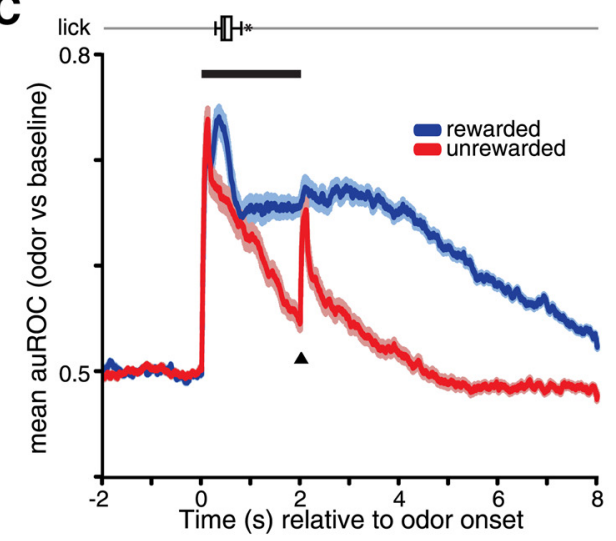

B

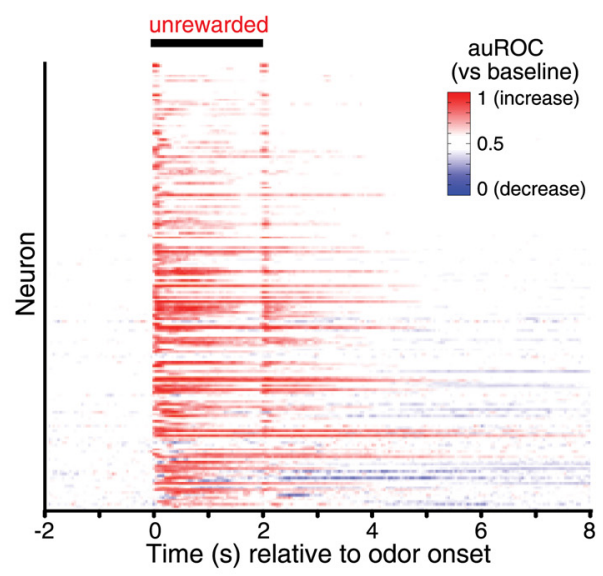

D

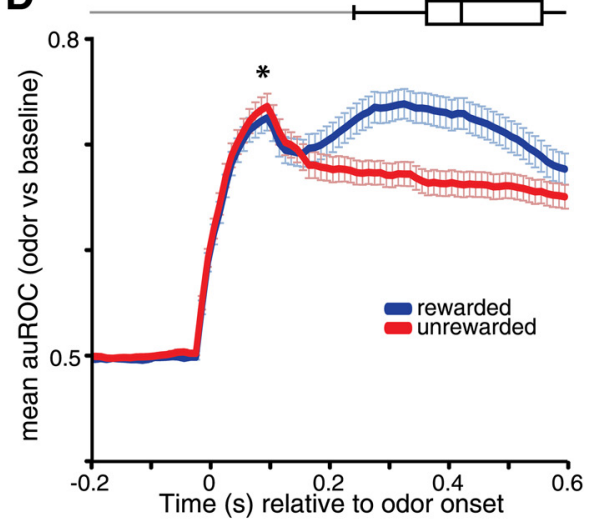

E

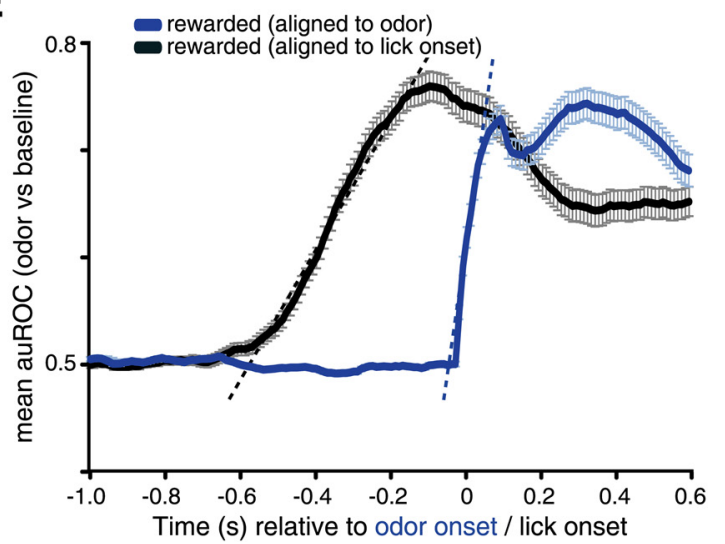

Figure 5. OT neurons display divergent responses to conditioned odors. $A, B$, Time course of odor-evoked changes in firing rate relative to baseline as indicated by auROC in response to rewarded (A) and unrewarded (B) odors. Each row represents one single neuron, and neurons are sorted by baseline rates during rewarded odor trials (top row $=$ lowest rate; $n=190$ neurons). $\boldsymbol{C}$, Population average auROC values for all task-responsive neurons ( $n=165$ neurons) in response to rewarded and unrewarded odors. An early divergence in auROC values occurred before the average behavioral response, with values $>0.5$ persisting for a longer duration in response to the rewarded odor. A transient increase in auROC coincided with odor offset during unrewarded trials (arrowhead). $\boldsymbol{D}$, The restricted timescale of C shows the onset of divergent auROC values before the average lick onset. The early increase in auROC, which is similar for both rewarded and unrewarded odors (asterisk), may reflect trial-associated multisensory cues and/or arousal (Morrison and Salzman, 2009; Wesson and Wilson, 2010). E, Average auROC values for rewarded trials when spikes times are aligned to odor onset versus lick onset, excluding trials identified with early lick onsets. Slopes of the initial rise were measured from $10 \%$ to $90 \%$ of the maximum auROC value (dashed lines), and were qualitatively steeper when aligned to odor onset than lick onset $(0.021 \mathrm{vs} 0.007$ auROC/10 $\mathrm{ms}$ bin, respectively). Horizontal boxplots show the range of average lick onsets for all sessions included in the average (median, $0.41 \mathrm{~s}$ ). An asterisk next to the boxplot indicates an identified outlier. Population values represent the mean \pm SEM.

rate from baseline using a sliding ROC analysis (Cohen et al., 2012; Veit and Nieder, 2013). Set on a $0-1$ scale, auROC values $>0.5$ indicate increases in firing rate relative to baseline (excitation), whereas values $<0.5$ indicate decreases (suppression). Task-responsive neurons typically displayed stimulus-evoked activity in response to both conditioned odors, but had higher fir- ing rates and more persistent activity during rewarded odor trials, as illustrated by an example single neuron in Figure $4 \mathrm{~A}$. Because both conditioned odors elicited increases in firing above the baseline rate in this neuron (Fig. $4 A$ ), the auROC increased $>0.5$ after odor onset for both odors when referenced against the baseline rate of this neuron (Fig. $4 B$ ). The improved discriminability of 
the response of the neuron to the rewarded odor is indicated by auROC values closer to 1 (perfect discriminability from baseline) and by the longer duration that values $>0.5$ were maintained (Fig. 4B). Across the population of single neurons, auROC values $>0.5$ were observed shortly $(<100 \mathrm{~ms})$ after the onset of both the rewarded and unrewarded odors. Notably, these responses were maintained for a longer duration in response to rewarded than unrewarded odors (Fig. $5 A, B$ ). This period of extended discharge often persisted beyond odor offset and after the behavioral decision was made. Activity during this time period may reflect encoding of the reward state. Some neurons were also observed to transiently $(<200 \mathrm{~ms})$ increase their discharge at odor offset for unrewarded odor trials (Fig. $5 B, C$ ). These neurons may also display a transient discharge following offset of the rewarded odor (Fig. 5A); however, this is difficult to detect given the persistent discharge associated with rewarded odor trials.

The above single-neuron examples illustrate that several factors, including the conditioned odors themselves, appear to modulate OT neuron activity. To examine responses associated with the odor cues, we restricted all subsequent analyses to the time window before the behavioral (lick) response. Average population auROC values were greater for rewarded than unrewarded odors during a $200 \mathrm{~ms}$ window before the average lick onset (Fig. $5 D$; paired $t$ test: $\left.t_{(164)}=4.796, p<0.0001\right)$. To test whether motor preparation or the execution of licking could contribute to the observed difference in odor trials, we first confirmed that our results were not dependent on trials with early lick onsets (i.e., those occurring $\leq 200 \mathrm{~ms}$ from odor onset). Only $2.3 \%$ of all trials met the criterion for an early lick onset. Exclusion of these trials did not influence our results (Fig. 5E), with mean auROC values to the rewarded odor being visually identical at all time bins to when these trials are included (Fig. 5, compare D, E, blue traces). Next, we compared auROC values in response to rewarded trials when spike times were aligned to lick onset instead of odor onset for each trial (Fig. $5 E$ ). Increases in auROC preceded lick onset by several hundreds of milliseconds, and the slope of the initial rise in auROC was less steep than when spike times were aligned to odor onset.

To test whether individual OT neurons preferentially encode one conditioned odor over the other (i.e., are "odor selective"), we directly quantified the discriminability of firing rates between the rewarded and unrewarded odors using a second ROC analysis (values $>0.5$ indicate increased firing to rewarded odors). Neurons were identified as odor selective if there were at least two consecutive significant auROC bins during a time period from odor onset to behavioral response (see Materials and Methods). As indicated by the auROC, a substantial population of taskresponsive neurons were odor selective (73\%, 120 of 165 neurons), with $83 \%$ of these odor-selective neurons (100 of 120) preferentially responding to the rewarded odor with higher firing rates than to the unrewarded odor (Fig. 6). Notably, these preferential responses occurred rapidly $(0.21 \pm 0.01 \mathrm{~s}$ latency from odor onset) and hundreds of milliseconds before the lick behavioral response (Fig. 6; median first lick latency, $0.41 \mathrm{~s}$ ). The finding that substantial changes in firing occur before lick onset indicates that odor valence information is present among OT neurons in a behaviorally relevant time window.

Arousal and demands associated with behavioral tasks can impact neural coding (Spitzer et al., 1988; Maunsell, 2004; Otazu et al., 2009). We hypothesized that the coding of conditioned odors within the OT is resilient to moderate changes in task demands. To test this, in separate behavioral sessions from a subset of the above mice, we used binary odor mixtures to increase the

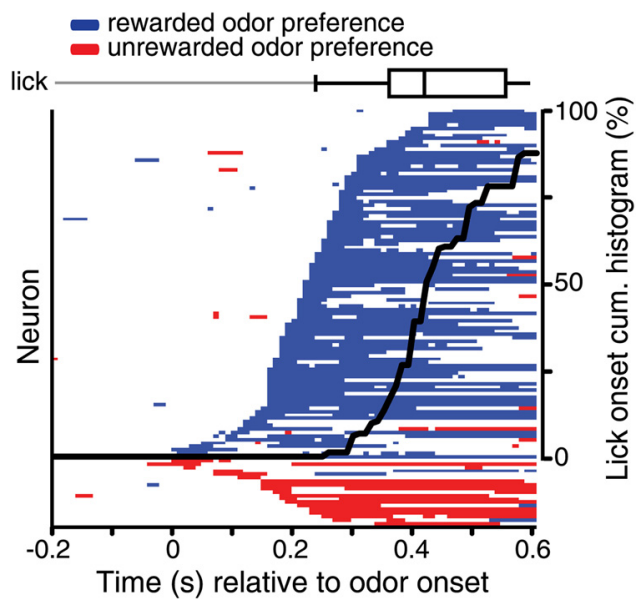

Figure 6. Odor selectivity occurs before behavioral response. Time course of significant odor selectivity overlaid with a cumulative (cum.) histogram of average lick onset (median, $0.41 \mathrm{~s}$; $n=120$ neurons). Sliding auROC values (rewarded vs unrewarded) were calculated in $10 \mathrm{~ms}$ bins and significance tested against a shuffled null distribution of values of $\sim 0.5$ (for details, see Materials and Methods). Neurons are sorted based on their odor preference and latency of odor selectivity. Horizontal boxplot shows the range of average lick onsets.

perceptual difficulty of the task (Uchida and Mainen, 2003; Abraham et al., 2004). Binary mixtures of the rewarded and unrewarded odors were presented, and the mice were rewarded if they responded to the mixture containing the greater proportion of the rewarded odor. As expected (Uchida and Mainen, 2003; Abraham et al., 2004), this paradigm resulted in reduced numbers of correct decisions made by the mice ( $71 \pm 2 \%$ correct; Fig. $7 A$ ). Similar to what was found during the perceptually coarse odor discriminations (Figs. 5D, 6), responses to the conditioned odor mixtures also diverged, with neurons again increasing their firing rate for the rewarded mixture (Fig. $7 B-D$; paired $t$ test, $t_{(72)}$ $=5.610, p<0.0001$ ). Thus, at least in the context of this comparison, the ability of OT neurons to encode odors within a behaviorally relevant time window is resilient to enhanced perceptual demands.

\section{Odor responses are highly plastic and encode the associated outcome of odors}

Are OT neurons selectively encoding the associated outcome of the odor? To address this, in a separate behavioral session we reversed the odor-outcome contingencies so that a previously rewarded odor is no longer rewarded and a previously unrewarded odor is now rewarded. A purely identity-encoding neuron should exhibit the same odor selectivity before and after reversal learning, whereas a neuron encoding the associative valence of an odor (rewarded or not) should reverse its odor preference; some combination of sensory and associative information may also be multiplexed within the same neuron (Roesch et al., 2007). Most animals learned the reversed contingencies within a single session, allowing for paired comparisons among the same neurons both before and after reversal $(n=58$; Figs. $8 A, B, 9 A)$. The example neuron illustrated in Figure $8 B$ displayed higher firing rates in response to the original rewarded odor (isopentyl acetate) than the unrewarded odor (ethyl propionate). After the associated odor outcomes were reversed, the behavioral performance of the animal dramatically decreased for two blocks, and firing rates of this neuron continued to be lower in response to ethyl propionate. As the animal learned the new odor-outcome contingencies, responses 
A

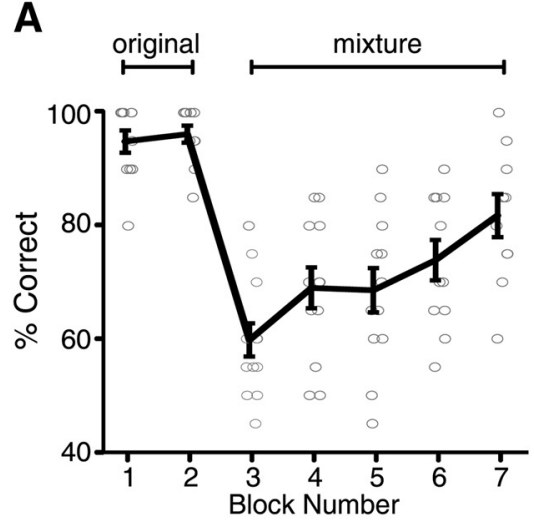

B

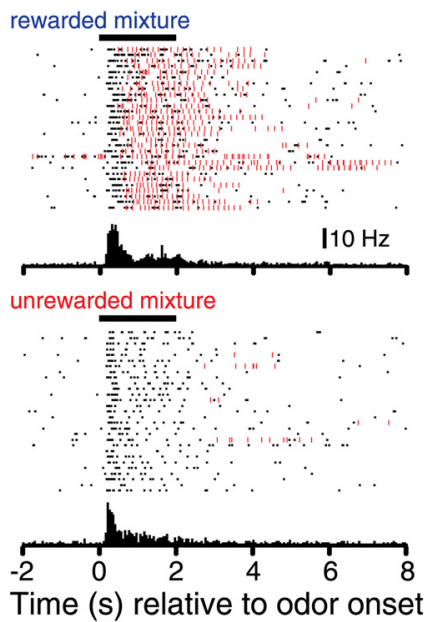

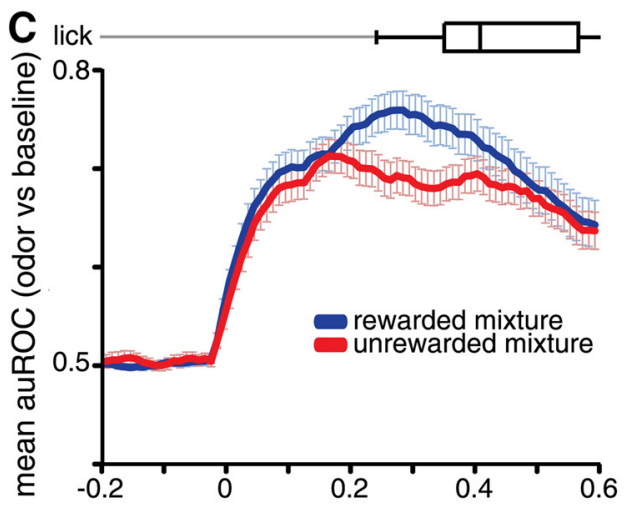

D

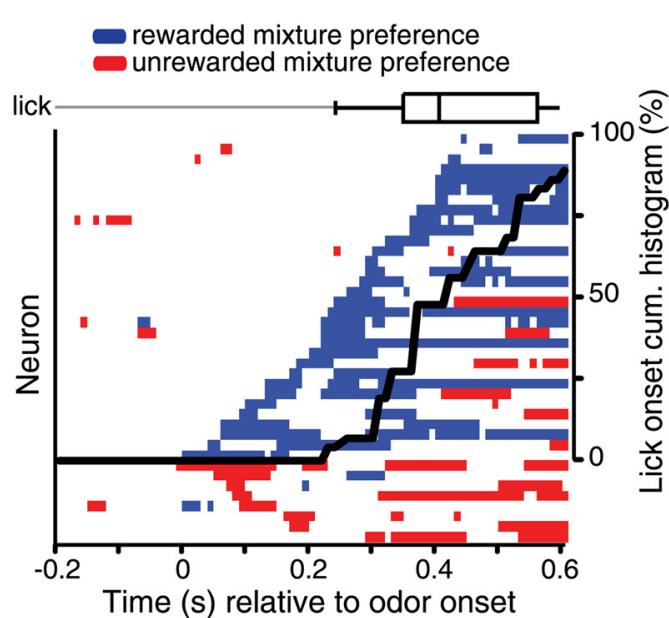

Figure 7. The OT encodes conditioned odors under increased perceptual demands. $\boldsymbol{A}$, Average behavioral performance across a binary odor mixture session. Odor pairs are presented as monomolecular odors for the first two blocks to ensure the maintenance of previous behavioral performance, followed immediately by several blocks of the odor mixtures. $\boldsymbol{B}$, Example single-neuron raster and peristimulus time histogram in response to conditioned odor mixtures on correct trials, with red vertical lines indicating the timing of detected licks (same neuron as in Fig. 4 ). $C$, Population average auROC values for all task-responsive neurons in a binary odor mixture discrimination task ( $n=73$ neurons) were greater for rewarded versus unrewarded odor mixtures. $\boldsymbol{D}$, Time course of significant odor mixture selectivity under increased task difficulty overlaid with a cumulative (cum.) histogram of average lick onset (median $=0.40 \mathrm{~s} ; n=41$ neurons). Horizontal boxplots show the range of average lick onsets for the rewarded mixture. Population values represent the mean \pm SEM.

gradually shifted toward increased firing rates for ethyl propionate. Mice typically began to lick in response to the new rewarded odor before they could withhold licking responses to the new unrewarded odor.

After successful reversal training, 69\% of 54 task-responsive neurons were odor selective, with $84 \%$ of these neurons firing preferentially for the newly conditioned rewarded odor (Fig. 9B). Again, significant divergence in firing occurred across the population (Fig. 9A; paired $t$ test: $t_{(53)}=2.330, p=0.0237$ ) and was observed before lick onset (Fig. $9 B$ ). Although a similar proportion of neurons displayed odor selectivity after reversal learning, the strength of discriminability indicated by average auROC magnitudes was reduced (Fig. 9C; paired $t$ test: $t_{(53)}=4.279, p<$ 0.0001 ). Only $11 \%$ of neurons (6 of 54) maintained the same odor preference after reversal, reflecting the encoding of odor identity, whereas $50 \%$ of neurons maintained the same odor valence preference (Fig. 9D). In addition, a large proportion of OT neurons (39\%) represented a combination of sensory and associative information. Nearly half of these "combinatorial" neurons reflected a gain in odor selectivity after reversal, whereas the other half lost odor selectivity with reversal. These data demonstrate that the bulk of OT neurons code for the associative valence of odors.

\section{Responses of OT neurons represent subsequent behavioral responses}

Do neural responses in the OT reflect the subsequent behavior displayed by the animal? To test this, in a subset of neurons recorded during the binary odor mixture discrimination task $(n=$ 76 of 88 neurons with sufficient error trial numbers), we compared auROC values from trials in which mice correctly identified the rewarded odor (hit) or unrewarded odor (correct reject) to trials in which the mice erroneously attempted to obtain a reward during the unrewarded odor (false alarm; Fig. 10A-C). There were an insufficient number of miss trials to include in the analysis. Significant auROC periods of trial response selectivity were calculated (Fig. 10C). We found that OT neurons preferentially fired for hit over correct reject trials (72\% of 29 neurons) and for false alarm over correct reject trials (73\% of 37 neurons). There was no clear preference when hit trials were compared with false alarms (48\% of 25 neurons had preference for hits). Together, firing rates of OT neurons during false alarm trials more closely resemble rates during hit trials. Thus, the increased firing rates of OT neurons in response to conditioned odors appear to reflect the subsequent instrumental response of the animal to obtain a reward and support the possible behavioral relevance of these coding schemes. 

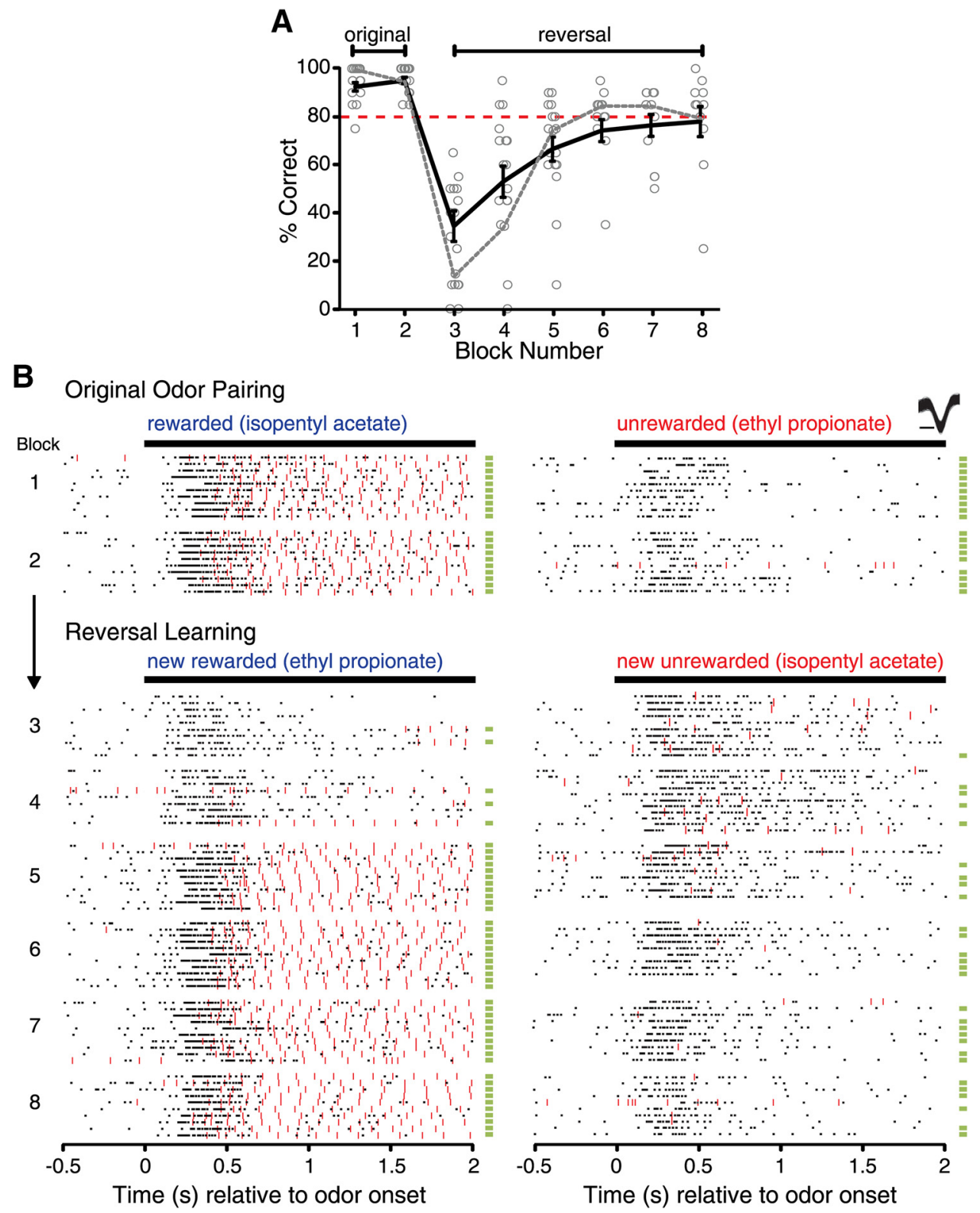

Figure 8. Reversal of associative outcome impacts behavioral performance and alters the response to conditioned odors in the $0 T$. A, Average behavioral performance across a reversal learning session. Original odor pairs were presented for the first two blocks to ensure the maintenance of previous behavioral performance, followed immediately by reversal of the odor-outcome contingencies. Data from individual mice are plotted in gray. Not all animals performed the same number of blocks. Dashed gray line tracks behavioral performance from the session illustrated in $\boldsymbol{B}$. Odor-evoked responses were analyzed from blocks in which the animal was performing at behavioral criterion ( $\geq 80 \%$; red dashed line). $\boldsymbol{B}$, Example single-neuron raster across a reversal session, with red vertical lines indicating the timing of individual trial licks. A green square to the right of a raster line indicates a correct trial. Inset, Overlapping waveforms of the isolated neuron. Calibration: $0.2 \mathrm{~ms}$. Black horizontal bars indicate the timing of odor stimuli.

\section{Discussion}

As the first study to describe odor-evoked activity among single neurons in the OT of behaving mice, we report that the firing rates of OT neurons robustly encode the learned valence of odors. We find that associative coding within the OT is rapid and highly plastic, with the majority of neurons preferentially firing for rewarded over unrewarded odors. Further, we find that odor coding within the OT is resilient against increased perceptual demands and appears to reflect the subsequent instrumental response of the animal. Our results unite two seemingly distinct theories of OT function-one as an olfactory processing node and one as a component of the reward system. By its anatomical connectivity, the OT provides a direct interface between the olfactory system and the striatum, which would allow these highly plastic odor representations to be translated into goal-directed behaviors.

\section{Insights into olfaction and associative odor coding among secondary olfactory structures}

The encoding of odors based upon their associative properties is observed within the olfactory bulb (Karpov, 1980; Wilson et al., 1987; Kay and Laurent, 1999; Doucette et al., 2011), which may inform odor valence coding in secondary olfactory structuresthose that receive direct monosynaptic input from the olfactory bulb - and vice versa. Among secondary olfactory structures, the piriform cortex has been most highly explored for its associative coding of odor information (for review, see Gottfried, 2010; Wilson and Sullivan, 2011; Nunez-Parra et al., 2014). Neurons in 

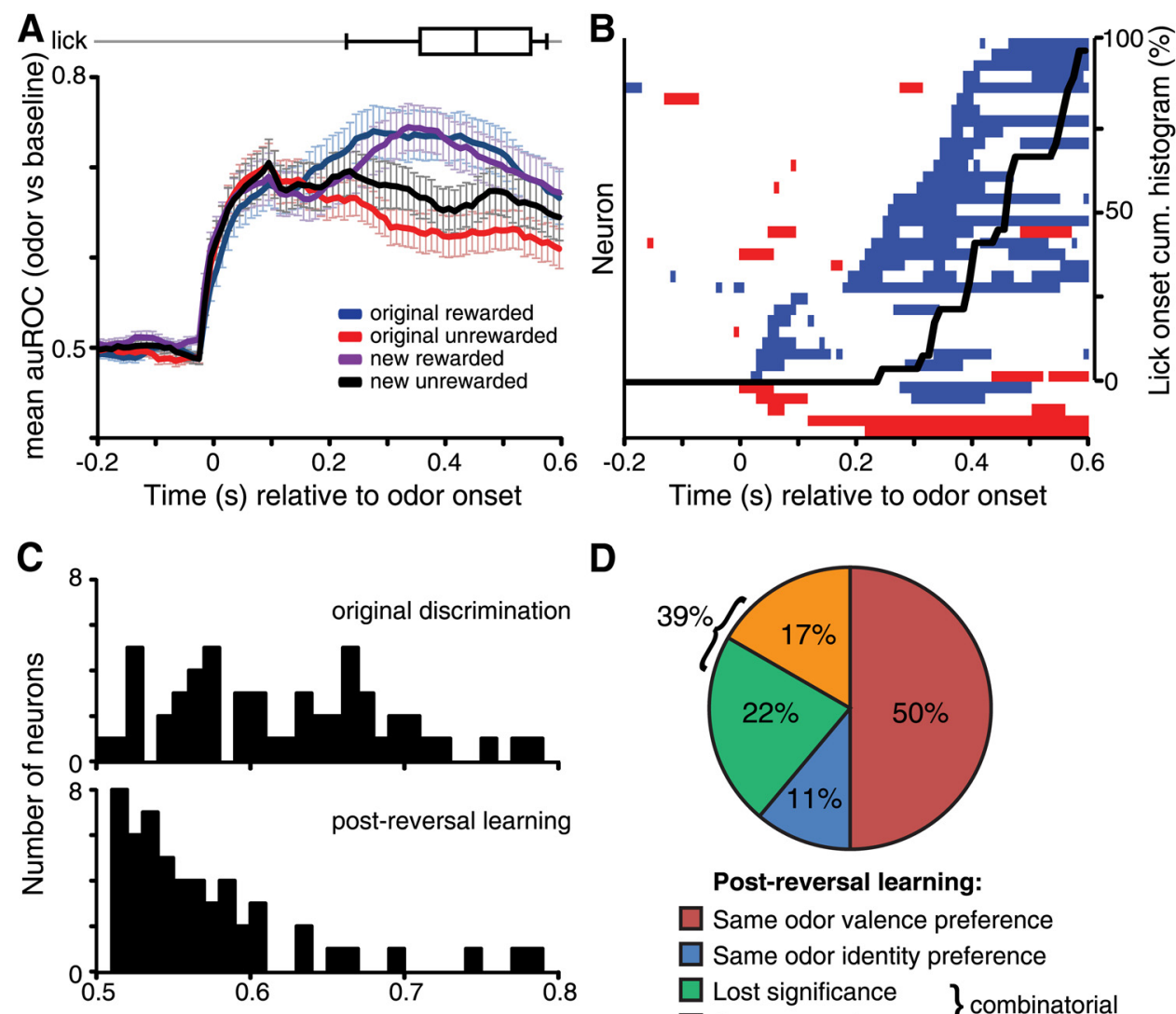

auROC magnitudes (rewarded vs unrewarded)

D

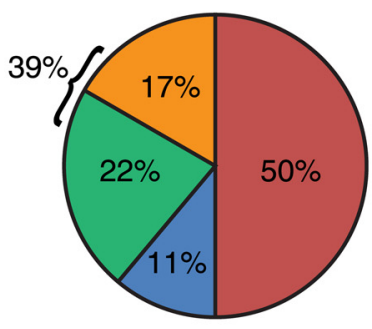

Post-reversal learning:

Same odor valence preference

$\square$ Same odor identity preference

Lost significance

Gained significance $\}$ combinatoria

Figure 9. Odor responses are highly plastic and encode the associative outcome. $A$, After reversal learning ( $n=54$ neurons), auROC values are maintained according to the associated outcome and not to chemical identity. Horizontal boxplot shows the range of average lick onsets to new rewarded odor presentation. $\boldsymbol{B}$, Time course of significant odor selectivity after reversal learning, overlaid with a cumulative (cum.) histogram of average lick onset (median onset, $0.46 \mathrm{~s} ; n=37$ neurons). Neurons are sorted based on their odor preference and latency of odor selectivity. $C$, Histograms displaying auROC magnitudes from all task-responsive neurons in $A$. Many neurons continued to display odor selectivity after reversal learning, but the average auROC magnitudes were reduced ( $p<0.0001$, paired $t$ test; $\left.t_{(53)}=4.279\right)$. $D$, After reversal learning, half of the 54 neurons maintained higher firing rates in response to the rewarded odor (associative encoding), whereas only $11 \%$ maintained their selectivity according to odor identity. The remaining combinatorial neurons either gained or lost significant odor-selective firing, suggesting a combination of associative and sensory coding. Population values represent the mean \pm SEM.

both the anterior and posterior regions of piriform cortex display odor cue selectivity, with greater firing rates in response to positively associated odors (Schoenbaum and Eichenbaum, 1995; Calu et al., 2007; Roesch et al., 2007; Gire et al., 2013). Our results add the OT to the list of secondary olfactory structures capable of coding odor valence. This associative coding is somewhat unexpected, given that the OT lacks an associative fiber network (Haberly and Price, 1978), which is hypothesized as the mediator of some forms of associative coding in the piriform cortex (Hasselmo et al., 1990; Barkai et al., 1994; Haberly, 2001; Wilson and Linster, 2008). Considering the associative coding in the piriform cortex (Calu et al., 2007; Wilson and Sullivan, 2011; Gire et al., 2013), our results suggest that the olfactory system uses parallel pathways to code for odor valence. Additional research is needed to test whether the piriform cortex and the OT uniquely contribute to odor valence coding. Further, while this work does demonstrate associative encoding in the OT, it will be important for future studies to explore the coding of odor identity by OT neurons in awake animals independent of associative influences.

Although many olfactory structures are heavily interconnected, the dense output from the OT into largely affective, motivational, and motor structures suggests that the coding of odor valence in the OT may be vital to a wide range of behaviors. This complements our understanding of associative coding in other downstream regions including the orbitofrontal cortex, amygdala, and nucleus accumbens (Schoenbaum and Eichenbaum, 1995; Schoenbaum et al., 1999; Anderson et al., 2003; Setlow et al., 2003; Roesch et al., 2007; Li et al., 2008). Determining the manners in which the OT interacts with other olfactory structures to facilitate sensory coding will be critical for understanding how the brain represents meaning to guide adaptive odor-based action selection.

In the present study, we used a lick/no-lick olfactory discrimination task to experimentally manipulate the associative valence of monomolecular odors that mice had no prior experience with. While this is a highly simplistic paradigm, we predict that our finding of odor valence coding in the OT will be observed in other odor learning paradigms and to innately rewarding odors (e.g., food odors, social odors). Indeed, the OT receives input from two regions representing rodent social odors-direct input from tufted cells within the ventral olfactory bulb (Scott et al., 1980; Restrepo et al., 2004; Martel and Baum, 2007) and indirect accessory olfactory input from the amygdala (Ubeda-Bañon et al., 2007, 2008)—supporting the hypothesis that OT neurons are involved in coding the valence of biologically relevant odors. Indeed, recent reports demonstrate that lesions of the medial OT impair social odor-guided behaviors (Agustín-Pavón et al., 2014; DiBenedictis et al., 2014). 
A

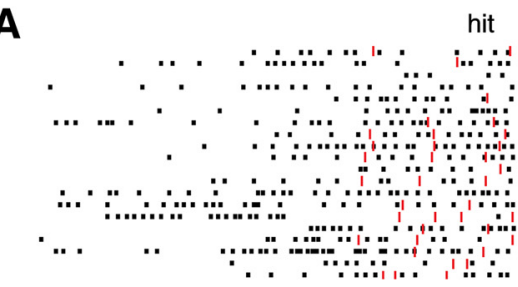

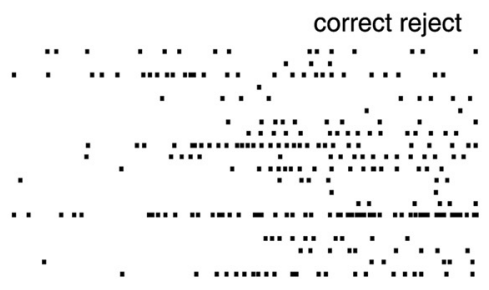

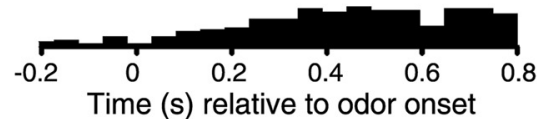

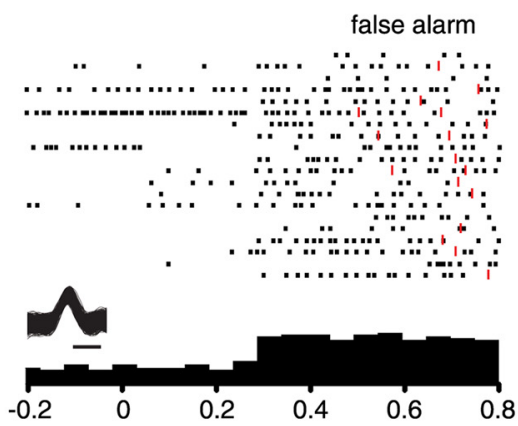
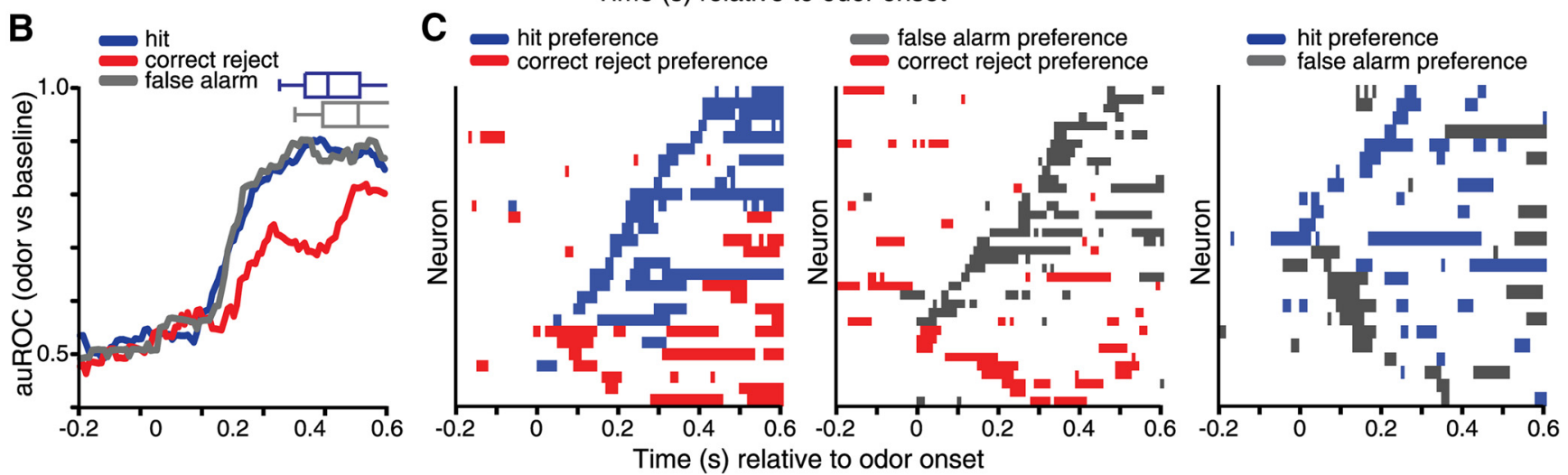

Figure 10. OT activity represents the subsequent behavioral response. $A$, Example single-neuron raster and peristimulus time histogram to rewarded and unrewarded odors separated by trial response type. Red vertical lines indicate the timing of detected licks on each trial. Inset, Overlapping waveforms of the isolated neuron. Calibration: $0.2 \mathrm{~ms}$. B, auROC calculated for each trial response from the neuron illustrated in $\boldsymbol{A}$, and the corresponding boxplots indicating the range of trial lick onsets for hit trials (blue; median onset, $0.61 \mathrm{~s}$ ) and false alarm trials (gray; median onset, $0.71 \mathrm{~s}$ ). False alarm auROC values closely match the hits. C, Time course of significant trial response selectivity for correct and error trial comparisons from 61 task-responsive neurons. Neurons are sorted based on their trial response preference and latency of selectivity $(n=29,37$, and 25 neurons, respectively).

\section{Implications for ventral striatum function and motivated behaviors}

The OT is a component of the ventral striatum reward circuitry that serves as a "limbic-motor interface" to facilitate behavioral learning (Mogenson et al., 1980; Cardinal et al., 2002; Ikemoto, 2007; van der Meer and Redish, 2011). The OT possesses dense reciprocal connectivity with the nucleus accumbens, ventral tegmental area, and multiple amygdaloid nuclei, as well as outputs to basal ganglia including the caudate-putamen (for review, see Wesson and Wilson, 2011). Based upon this, we predict that the acquired odor valence coding observed within the OT could influence goal-directed behaviors through direct outputs to the basal ganglia (Fallon, 1983). The role of the ventral striatum in associative encoding has been largely investigated within the nucleus accumbens. In the nucleus accumbens, cue-evoked responses are related to the associated outcome of a stimulus, rather than its sensory features, and are also sensitive to primary reinforcers themselves (Williams et al., 1993; Schultz et al., 2000; Carelli, 2002). Here we provide data demonstrating that a previously underappreciated region of the ventral striatum also engages in associative encoding. In that sense, we believe that this work complements our understanding of how the ventral striatum encodes stimulus valence to guide instrumental behavior.

As in any go/no-go paradigm, the motor preparation and execution of behavior (i.e., licking) could contribute to the differences we observed between rewarded and unrewarded odor trials. In the present study, odors were delivered for a $2 \mathrm{~s}$ duration, and mice were allowed to make the go response at any point during the odor presentation, on average only re- quiring $0.41 \mathrm{~s}$ to lick for reward. To ensure that differences in firing were not related to licking, we restricted all analyses to a time period from odor onset to the initiation of licking, confirmed that auROC values for odor discrimination sessions did not depend on trials with early lick onsets, and found that increases in the auROC preceded lick onset and had a more shallow rise when spike times were aligned to lick onset rather than odor onset. While these analyses suggest that the divergent responses in the OT are determined by the associative properties of the odors, it is possible that some neural activity within the OT is related to the initiation of goal-directed behavior, similar to what has been observed in the orbitofrontal cortex (Gutierrez et al., 2006). Additional features of OT responses may be resolved in future studies by delaying primary reinforcers from the odor cues or by using alternative task designs.

\section{Conclusion}

In summary, our finding of associative encoding within the OT complements our understanding of how the ventral striatum encodes information to guide instrumental behavior. By using an olfactory discrimination task, we have discovered one more region of the olfactory system that is capable of conveying behaviorally relevant neural codes that are sensitive to the associative outcome of the odor. Elucidating the mechanisms that allow the OT to accomplish this task in such a robust and rapid manner, and testing the precise contributions of these transformations to behavior, will be critical in understanding the neural basis of odor-guided behaviors. 


\section{References}

Abraham NM, Spors H, Carleton A, Margrie TW, Kuner T, Schaefer AT (2004) Maintaining accuracy at the expense of speed: stimulus similarity defines odor discrimination time in mice. Neuron 44:865-876. CrossRef Medline

Agustín-Pavón C, Martínez-García F, Lanuza E (2014) Focal lesions within the ventral striato-pallidum abolish attraction for male chemosignals in female mice. Behav Brain Res 259:292-296. CrossRef Medline

Anderson AK, Christoff K, Stappen I, Panitz D, Ghahremani DG, Glover G, Gabrieli JD, Sobel N (2003) Dissociated neural representations of intensity and valence in human olfaction. Nat Neurosci 6:196-202. CrossRef Medline

Barkai E, Bergman RE, Horwitz G, Hasselmo ME (1994) Modulation of associative memory function in a biophysical simulation of rat piriform cortex. J Neurophysiol 72:659-677. Medline

Berridge KC, Aldridge JW (2008) Decision utility, the brain, and pursuit of hedonic goals. Soc Cogn 26:621-646. CrossRef Medline

Calu DJ, Roesch MR, Stalnaker TA, Schoenbaum G (2007) Associative encoding in posterior piriform cortex during odor discrimination and reversal learning. Cereb Cortex 17:1342-1349. CrossRef Medline

Cardinal RN, Parkinson JA, Hall J, Everitt BJ (2002) Emotion and motivation: the role of the amygdala, ventral striatum, and prefrontal cortex. Neurosci Biobehav Rev 26:321-352. CrossRef Medline

Carelli RM (2002) Nucleus accumbens cell firing during goal-directed behaviors for cocaine vs. "natural" reinforcement. Physiol Behav 76:379387. CrossRef Medline

Carlson KS, Dillione MR, Wesson DW (2014) Odor-and state-dependent olfactory tubercle local field potential dynamics in awake rats. J Neurophysiol 111:2109-2123. CrossRef Medline

Chikazoe J, Lee DH, Kriegeskorte N, Anderson AK (2014) Population coding of affect across stimuli, modalities and individuals. Nat Neurosci 17: 1114-1122. CrossRef Medline

Cohen JY, Haesler S, Vong L, Lowell BB, Uchida N (2012) Neuron-typespecific signals for reward and punishment in the ventral tegmental area. Nature 482:85-88. CrossRef Medline

Cohen Y, Reuveni I, Barkai E, Maroun M (2008) Olfactory learninginduced long-lasting enhancement of descending and ascending synaptic transmission to the piriform cortex. J Neurosci 28:6664-6669. CrossRef Medline

de Olmos JS, Heimer L (1999) The concepts of the ventral striatopallidal system and extended amygdala. Ann N Y Acad Sci 877:1-32. CrossRef Medline

DiBenedictis BT, Olugbemi AO, Baum MJ, CherryJA (2014) 6-Hydroxydopamine lesions of the anteromedial ventral striatum impair opposite-sex urinary odor preference in female mice. Behav Brain Res 274:243-247. CrossRef Medline

Doty RL (1986) Odor-guided behavior in mammals. Experentia 42:257271. CrossRef

Doucette W, Gire DH, Whitesell J, Carmean V, Lucero MT, Restrepo D (2011) Associative cortex features in the first olfactory brain relay station. Neuron 69:1176-1187. CrossRef Medline

Fallon JH (1983) The islands of Calleja complex of rat basal forebrain, II. Connections of medium and large sized cells. Brain Res Bull 10:179-199.

Gire DH, Whitesell JD, Doucette W, Restrepo D (2013) Information for decision-making and stimulus identification is multiplexed in sensory cortex. Nat Neurosci 16:991-993. CrossRef Medline

Gottfried JA (2009) Olfaction and its pleasures: human neuroimaging perspectives. In: Pleasures of the brain (Kringelbach ML, Berridge KC, eds), pp 125-145. New York: Oxford UP.

Gottfried JA (2010) Central mechanisms of odour object perception. Nat Rev Neurosci 11:628-641. CrossRef Medline

Green DM, Swets JA (1966) Signal detection theory and psychophysics. New York: Wiley.

Gutierrez R, Carmena JM, Nicolelis MA, Simon SA (2006) Orbitofrontal ensemble activity monitors licking and distinguishes among natural rewards. J Neurophysiol 95:119-133. CrossRef Medline

Haberly LB (2001) Parallel-distributed processing in olfactory cortex: new insights from morphological and physiological analysis of neuronal circuitry. Chem Senses 26:551-576. CrossRef Medline

Haberly LB, Price JL (1978) Association and commissural fiber systems of the olfactory cortex of the rat. I. Systems originating in the piriform cortex and adjacent areas. J Comp Neurol 178:711-740. CrossRef Medline
Hasselmo ME, Wilson MA, Anderson BP, Bower JM (1990) Associative memory function in piriform (olfactory) cortex: computational modeling and neuropharmacology. Cold Spring Harb Symp Quant Biol 55:599610. CrossRef Medline

Ikemoto S (2003) Involvement of the olfactory tubercle in cocaine reward: intracranial self-administration studies. J Neurosci 23:9305-9311. Medline

Ikemoto S (2007) Dopamine reward circuitry: two projection systems from the ventral midbrain to the nucleus accumbens-olfactory tubercle complex. Brain Res Rev 56:27-78. CrossRef Medline

Ikemoto S, Qin M, Liu ZH (2005) The functional divide for primary reinforcement of $\mathrm{D}$-amphetamine lies between the medial and lateral ventral striatum: is the division of the accumbens core, shell, and olfactory tubercle valid? J Neurosci 25:5061-5065. CrossRef Medline

Karpov AP (1980) Analysis of neuron activity in the rabbit's olfactory bulb during food-acquisition behavior. In: Neural mechanisms of goaldirected behavior and learning (Thompson RF, Hicks LH, Shvyrkov VB, eds), pp 273-282. New York: Academic.

Kay LM, Laurent G (1999) Odor- and context-dependent modulation of mitral cell activity in behaving rats. Nat Neurosci 2:1003-1009. CrossRef Medline

Kumar S, von Kriegstein K, Friston K, Griffiths TD (2012) Features versus feelings: dissociable representations of the acoustic features and valence of aversive sounds. J Neurosci 32:14184-14192. CrossRef Medline

Li W, Howard JD, Parrish TB, Gottfried JA (2008) Aversive learning enhances perceptual and cortical discrimination of indiscriminable odor cues. Science 319:1842-1845. CrossRef Medline

Litaudon P, Mouly AM, Sullivan R, Gervais R, Cattarelli M (1997) Learning-induced changes in rat piriform cortex activity mapped using multisite recording with voltage sensitive dye. Eur J Neurosci 9:15931602. CrossRef Medline

Martel KL, Baum MJ (2007) Sexually dimorphic activation of the accessory, but not the main, olfactory bulb in mice by urinary volatiles. Eur J Neurosci 26:463-475. CrossRef Medline

Maunsell JH (2004) Neuronal representations of cognitive state: reward or attention. Trends Cogn Sci 8:261-265. CrossRef Medline

Mogenson GJ, Jones DL, Yim CY (1980) From motivation to action: functional interface between the limbic system and the motor system. Prog Neurobiol 14:69-97. CrossRef Medline

Morrison SE, Salzman CD (2009) The convergence of information about rewarding and aversive stimuli in single neurons. J Neurosci 29:1147111483. CrossRef Medline

Murakami M, Kashiwadani H, Kirino Y, Mori K (2005) State-dependent sensory gating in olfactory cortex. Neuron 46:285-296. CrossRef Medline

Narikiyo K, Manabe H, Mori K (2014) Sharp wave-associated synchronized inputs from the piriform cortex activate olfactory tubercle neurons during slow-wave sleep. J Neurophysiol 111:72-81. CrossRef Medline

Nunez-Parra A, Li A, Restrepo D (2014) Coding odor identity and odor value in awake rodents. In: Progress in brain res (Barkai E, Wilson DA, eds), pp 205-222. New York: Elsevier.

Otazu GH, Tai LH, Yang Y, Zador AM (2009) Engaging in an auditory task suppresses responses in auditory cortex. Nat Neurosci 12:646-654. CrossRef Medline

Pager J (1974) A selective modulation of the olfactory bulb electrical activity in relation to the learning of palatability in hungry and satiated rats. Physiol Behav 12:189-195. CrossRef Medline

Paxinos G, Franklin K (2000) The mouse brain in stereotaxic coordinates, Ed 2. San Diego: Academic

Payton CA, Wilson DA, Wesson DW (2012) Parallel odor processing by two anatomically distinct olfactory bulb target structures. PLoS One 7:e34926. CrossRef Medline

Pessoa L, Adolphs R (2010) Emotion processing and the amygdala: from a "low road" to "many roads" of evaluating biological significance. Nat Rev Neurosci 11:773-783. CrossRef Medline

Prado-Alcalá R, Wise RA (1984) Brain stimulation reward and dopamine terminal fields. I. Caudate-putamen, nucleus accumbens and amygdala. Brain Res 297:265-273. CrossRef Medline

Rampin O, Bellier C, Maurin Y (2012) Electrophysiological responses of rat olfactory tubercle neurons to biologically relevant odours. Eur J Neurosci 35:97-105. CrossRef Medline

Restrepo D, Arellano J, Oliva AM, Schaefer ML, Lin W (2004) Emerging views on the distinct but related roles of the main and accessory olfactory 
systems in responsiveness to chemosensory signals in mice. Horm Behav 46:247-256. CrossRef Medline

Roesch MR, Stalnaker TA, Schoenbaum G (2007) Associative encoding in anterior piriform cortex versus orbitofrontal cortex during odor discrimination and reversal learning. Cereb Cortex 17:643-652. CrossRef Medline

Schoenbaum G, Eichenbaum H (1995) Information coding in the rodent prefrontal cortex. I. Single-neuron activity in orbitofrontal cortex compared with that in pyriform cortex. J Neurophysiol 74:733-750. Medline

Schoenbaum G, Chiba AA, Gallagher M (1999) Neural encoding in orbitofrontal cortex and basolateral amygdala during olfactory discrimination learning. J Neurosci 19:1876-1884. Medline

Schultz W, Tremblay L, Hollerman JR (2000) Reward processing in primate orbitofrontal cortex and basal ganglia. Cereb Cortex 10:272-284. CrossRef Medline

Scott JW (1986) The olfactory bulb and central pathways. Experientia 42: 223-232. CrossRef Medline

Scott JW, McBride RL, Schneider SP (1980) The organization of projections from the olfactory bulb to the piriform cortex and olfactory tubercle in the rat. J Comp Neurol 194:519-534. CrossRef Medline

Setlow B, Schoenbaum G, Gallagher M (2003) Neural encoding in ventral striatum during olfactory discrimination learning. Neuron 38:625-636. CrossRef Medline

Shipley MT, Adamek GD (1984) The connections of the mouse olfactory bulb: a study using orthograde and retrograde transport of wheat germ agglutinin conjugated to horseradish peroxidase. Brain Res Bull 12:669688. CrossRef Medline

Slotnick B (2001) Animal cognition and the rat olfactory system. Trends Cogn Sci 5:216-222. CrossRef Medline

Spitzer H, Desimone R, Moran J (1988) Increased attention enhances both behavioral and neuronal performance. Science 240:338-340. CrossRef Medline

Thompson KG, Hanes DP, Bichot NP, Schall JD (1996) Perceptual and motor processing stages identified in the activity of macaque frontal eye field neurons during visual search. J Neurophysiol 76:4040-4055. Medline

Ubeda-Bañon I, Novejarque A, Mohedano-Moriano A, Pro-Sistiaga P, de la Rosa-Prieto C, Insausti R, Martinez-Garcia F, Lanuza E, MartinezMarcos A (2007) Projections from the posterolateral olfactory amygdala to the ventral striatum: neural basis for reinforcing properties of chemical stimuli. BMC Neurosci 8:103. CrossRef Medline
Ubeda-Bañon I, Novejarque A, Mohedano-Moriano A, Pro-Sistiaga P, Insausti R, Martinez-Garcia F, Lanuza E, Martinez-Marcos A (2008) Vomeronasal inputs to the rodent ventral striatum. Brain Res Bull 75:467-473. CrossRef Medline

Uchida N, Mainen ZF (2003) Speed and accuracy of olfactory discrimination in the rat. Nat Neurosci 6:1224-1229. CrossRef Medline

van der Meer MA, Redish AD (2011) Ventral striatum: a critical look at models of learning and evaluation. Curr Opin Neurobiol 21:387-392. CrossRef Medline

Veit L, Nieder A (2013) Abstract rule neurons in the endbrain support intelligent behaviour in corvid songbirds. Nat Commun 4:2878. CrossRef Medline

Veldhuizen MG, Rudenga KJ, Small DM (2009) The pleasure of taste, flavor, and food. In: Pleasures of the brain (Kringelbach ML, Berridge KC, eds), pp 146-168. New York: Oxford UP.

Verhagen JV, Wesson DW, Netoff TI, White JA, Wachowiak M (2007) Sniffing controls an adaptive filter of sensory input to the olfactory bulb. Nat Neurosci 10:631-639. CrossRef Medline

Wesson DW, Wilson DA (2010) Smelling sounds: olfactory-auditory sensory convergence in the olfactory tubercle. J Neurosci 30:3013-3021. CrossRef Medline

Wesson DW, Wilson DA (2011) Sniffing out the contributions of the olfactory tubercle to the sense of smell: hedonics, sensory integration, and more? Neurosci Biobehav Rev 35:655-668. CrossRef Medline

Wesson DW, Donahou TN, Johnson MO, Wachowiak M (2008) Sniffing behavior of mice during performance in odor-guided tasks. Chem Senses 33:581-596. CrossRef Medline

Williams GV, Rolls ET, Leonard CM, Stern C (1993) Neuronal responses in the ventral striatum of the behaving macaque. Behav Brain Res 55:243252. CrossRef Medline

Wilson DA, Linster C (2008) Neurobiology of a simple memory. J Neurophysiol 100:2-7. CrossRef Medline

Wilson DA, Sullivan RM (2011) Cortical processing of odor objects. Neuron 72:506-519. CrossRef Medline

Wilson DA, Sullivan RM, Leon M (1987) Single-unit analysis of postnatal olfactory learning: modified olfactory bulb output response patterns to learned attractive odors. J Neurosci 7:3154-3162. Medline

Zelano C, Bensafi M, Porter J, Mainland J, Johnson B, Bremner E, Telles C, Khan R, Sobel N (2005) Attentional modulation in human primary olfactory cortex. Nat Neurosci 8:114-120. CrossRef Medline 